\title{
Atividade Alelopática de Extratos Brutos de Três Espécies de Copaifera (LEguminosae-CAESALPINIOIDEAE) ${ }^{1}$
}

\author{
Allelophatic Activity of Crude Extracts from Three Species of Copaifera \\ (Leguminosae-Caesalpinioidedae)
}

\author{
SOUZA FILHO, A.P.S. ${ }^{2}$, GURGEL, E.S.C. ${ }^{3}$, QUEIROZ, M.S.M.. e SANTOS, J.U.M. ${ }^{3}$
}

\begin{abstract}
RESUMO - Nos últimos anos, atenção especial foi dada aos compostos químicos envolvidos na interação entre plantas, especialmente quando se sabe das possibilidades do seu uso em estratégia de manejo de plantas daninhas. A Amazônia, pela sua megabiodiversidade e abundância de espécies vegetais, pode oferecer excelente oportunidade para a descoberta de inovadoras moléculas químicas com potencial de uso na atividade agrícola. Dessa forma, neste trabalho analisou-se, comparativamente, a atividade potencialmente alelopática de três espécies de Copaifera, caracterizando-se as variações na intensidade dos efeitos alelopáticos em função da espécie doadora, da fração da planta e da polaridade dos constituintes químicos. Extratos hexânico e etanólico, preparados a 1,0\% a partir de folhas, galhos e cascas de Copaifera duckei, C. martii e C. reticulata, foram testados sobre a germinação de sementes e o desenvolvimento da raiz das plantas daninhas malícia (Mimosa pudica) e mata-pasto (Senna obtusifolia). Observaram-se variações nas intensidades dos efeitos em função das variáveis estudadas. O extrato etanólico de folhas e o de galhos de C. martii e C. reticulata apresentaram alto potencial para inibir a germinação de sementes, sobretudo da espécie malícia. A espécie C. duckei evidenciou baixo potencial alelopático inibitório na germinação das duas espécies receptoras. Cascas, folhas e galhos de C. duckei apresentaram potencial inibitório mais expressivo sobre o desenvolvimento da raiz, com destaque para as folhas. Compostos químicos apolares e polares estão envolvidos na atividade alelopática da espécie C. duckei, com ênfase maior para os compostos apolares. Diferentemente, para C. martii e C. reticulata, compostos polares estão envolvidos, preferencialmente, na atividade inibitória evidenciada por essas espécies, notadamente aqueles localizados nas folhas e cascas. Comparativamente, a tendência observada foi de que a espécie receptora malícia demonstrou maior sensibilidade aos efeitos alelopáticos dos extratos, especialmente no bioensaio de germinação.
\end{abstract}

Palavras-chave: alelopatia, extrato hexânico, extrato etanólico, inibição, parte da planta.

\begin{abstract}
For the past few years, special attention has been given to chemical composites involved in interaction between plants, especially when the potential of their use in weed management is known. The Amazon region with its enormous biodiversity and abundance of plant species may offer excellent opportunities for the discovery of innovative chemical molecules capable of being used in agriculture. Thus, in this paper, a comparative analysis was made between the potential allelopathic activity of three species of Copaifera, characterizing the variations of the intensity of the allelopathic effects of the donating species, plant fraction and chemical component polarity. Hexanic and ethanolic extracts, prepared at 1.0\% from the leaves, branches and barks of Copaifera duckei, C. martii and C. reticulata, were tested on seed germination and development of Mimosa pudica and Senna obtusifolia weed roots. The results showed that the intensity of the effects varied according to the variables studied. The ethanolic extract of $\mathbf{C}$. martii and $\mathbf{C}$. reticulata leaves and barks showed high potential to inhibit seed germination, especially of $\boldsymbol{M}$. pudica species.
\end{abstract}

Recebido para publicação em 16.10.2009 e na forma revisada em 12.11.2010.

2 Engo-Agrōe, Dr., Embrapa Amazônia Oriental, Trav. Dr. Enéas Pinheiro, S/N. 66.095-100 Belém-PA; ${ }^{3}$ Engo-Agrōe, Dr., Museu Paraense Emílio Goeldi, Caixa Postal 399, 66040-170 Belém-PA; ${ }^{4}$ Bióloga, Dra., Instituto Nacional de Pesquisas da Amazônia, Caixa Postal 478, 69011-970 Manaus-AM.

Planta Daninha, Viçosa-MG, v. 28, n. 4, p. 743-751, 2010 
The species C. duckei showed low allelopathic inhibitory potential in the germination of two receptor species. Barks, branches and especially leaves of $\boldsymbol{C}$. duckei presented more expressive inhibitory potential for root development. Polar, and especially non-polar chemical composites, are involved in the allelopathic activity of $\boldsymbol{C}$. duckei. Differently for C. martii and C. reticulata, the polar composites are preferentially involved in the inhibitory activity evidenced by these species, especially those located on the leaves and barks. Comparatively, it was observed that the weed species receptor tended to show more sensitivity to the allelopathic effects of the extracts, especially in the germination bioassay.

Keywords: allelopathy, hexanic extract, ethanolic extract, inhibition, part of the plant.

\section{INTRODUÇÃO}

Interações do tipo planta x planta, mediadas por compostos químicos, e suas implicações na dinâmica das espécies que compõem os agrossistemas assumiram, nos últimos anos, papel relevante na interpretação do papel ecológico das espécies. A esse fenômeno o pesquisador alemão Molisch, em 1937, chamou de alelopatia (Rice, 1987); desde então, o interesse por essa área do conhecimento só tem crescido.

Com a percepção de que as substâncias químicas envolvidas nessas interações poderiam ser utilizadas como estratégia de manejo de plantas daninhas, diferentes pesquisas, envolvendo a prospecção de atividade alelopática, foram desenvolvidas em diferentes laboratórios do mundo. O Brasil também acompanhou essa tendência e, em passado recente, muitos trabalhos foram desenvolvidos com enfoque na alelopatia.

Em sintese, os trabalhos de prospecção envolvem, em sua fase inicial, o uso de extratos brutos, aquosos ou alcoólicos e, em alguns poucos casos, extratos hidroalcoólicos.

Basicamente, a avaliação da atividade alelopática é realizada em bioensaios específicos, procurando-se aquilatar efeitos sobre a germinação de sementes e o desenvolvimento da raiz e do hipocótilo (Souza Filho et al., 1997, 1999; Souza Filho \& Alves, 2000a; Tefera, 2002; Shiraishi et al., 2002; Berger \& Schagerl, 2003; Iqbal et al., 2004; Periotto et al., 2004). Diferenças expressivas são observadas entre esses trabalhos tanto em relação à fonte de planta, à parte da planta, como também em relação às concentrações de extratos.

Os avanços nessa linha dependem, em primeira instância, do fator diversidade biológica disponivel para as prospecções; nesse sentido, a floresta amazônica é pródiga pela diversidade e abundância de sua flora, podendo colocar à disposição da comunidade científica espécies de plantas ainda totalmente desconhecidas quimicamente. Em passado recente, alguns trabalhos foram desenvolvidos com o objetivo de identificar e caracterizar atividade alelopática em espécies nativas da Amazônia. O resultado desses esforços promoveu a identificação de várias substâncias químicas com atividade alelopática, como pode ser conferido nos trabalhos de Souza Filho et al. (2005), Santos et al. (2007/2008), Arruda et al. (2005) e Lobo et al. (2008).

Entre os muitos componentes da flora nativa encontrados na Amazônia, merece distinção a família Leguminosae, que conta aproximadamente com 19.325 espécies, distribuídas em 727 gêneros (Lewis et al., 2005). Ela representa um dos principais e mais importantes grupos de plantas superiores; trata-se da terceira maior familia de angiospermas, depois das Asteraceae (Compositae) e Orchidaceae. Ela destaca-se, ainda, na composição das florestas nativas brasileiras (Marchiori, 1997). Segundo Wojciechowski et al. (2004), depois de Poaceae, é a familia economicamente mais importante. Na região, a família conta com aproximadamente 3.100 taxa específicos e infraespecíficos, distribuídos em 198 gêneros (Silva et al., 1989).

Dentre os gêneros da família Leguminosae, destaca-se a Copaifera, pertencente à Caesalpinioideae, provavelmente composta por 28 espécies, das quais 16 são encontradas no Brasil. Esse gênero ocorre na África e América Central, com quatro espécies; América do Sul, com 37; e provavelmente apenas uma na Ásia (Dwyer, 1951). 
Dentre as espécies da Amazônia legal, destacam-se Copaifera duckei, C. glycicarpa, C. guyanensis, C. martii, C. multijuga, C. paupera, C. piresii, Copaifera pubiflora e Copaifera reticulata (Martins-da-Silva, 2006).

As copaíferas, na Amazônia, apresentam ampla distribuição geográfica, ocorrendo desde o médio Tapajós até a Amazônia ocidental (Amazonas e Rondônia). Ocorre com frequência em matas de terra firme, em solos argilosos e, às vezes, nos arenosos, como Copaifera martii (1949). Podem ser arbustos ou árvores, que atingem até $40 \mathrm{~m}$ de altura. São conhecidas popularmente por "copaíba", "copaibeira", "árvore milagrosa", "pau-d'óleo" e outros; os indígenas denominavam o produto milagroso de "copahu" ou "copaiva" (Ferreira, 1988; Martins-da-Silva, 2006), oriundo de "kupa' iwa", da lingua tupi, que, segundo Cunha (1999), em tupi quer dizer planta da qual se extrai um óleo com propriedades medicinais.

Informações químicas de folhas, galhos e cascas das espécies $C$. duckei, $C$. reticulata e C. martii são escassas, o que revela a necessidade do desenvolvimento de pesquisa no sentido de avançar nos conhecimentos de seu potencial alelopático.

Este trabalho teve por objetivo analisar, comparativamente, o potencial efeito alelopático de três espécies de Copaifera, identificando e caracterizando as variações na intensidade dos efeitos em função da espécie doadora, da fração da planta e da polaridade do extrato alcoólico.

\section{MATERIAL E MÉTODOS}

\section{Coleta de material botânico e identificação taxonômica}

Foram coletadas amostras de cascas, folhas e galhos de Copaifera duckei, C. martii e $C$. reticulata, de matrizes localizadas no nordeste do Estado do Pará, no distrito de Mosqueiro, pertencente à cidade de Belém, na fazenda Mari-Mari, localizada às margens da PA 391, no km 28, e em Barcarena, na Vila dos Cabanos, na Praia do Caripi.

Para cada matriz, coletou-se material botânico fértil, contendo frutos, os quais foram identificados e incorporados ao acervo do MG
(Herbário do Museu Paraense Emílio Goeldi, Belém - Pará) e do IAN (Embrapa Amazônia Oriental, Belém - Pará) Copaifera duckei (IAN 175.605), Copaifera martii (IAN 176.276) e Copaifera reticulata (MG 186.090).

\section{Secagem e trituração do material botânico coletado e procedimento de extração exaustiva}

As diferentes frações das plantas foram secas em estufa de circulação forçada de ar , em temperatura constante de $40{ }^{\circ} \mathrm{C}$, por 72 horas, sendo em seguida trituradas em moinho tipo Wiley. Posteriormente, realizouse a extração exaustiva, sucessivamente com os solventes hexano e etanol. O material botânico inicialmente permaneceu em 1 litro de hexano por 24 horas; posteriormente, adicionou-se mais 1 litro e, após 24 horas, realizou-se mais uma extração, adotando-se o mesmo processo para o solvente etanol, para então concentrar os extratos em rotavapor e, a seguir, acondicioná-los em vidros âmbar.

\section{Análise da atividade alelopática de extratos brutos}

Foi monitorada a germinação das sementes em períodos de 10 dias, com contagens diárias e eliminação das sementes germinadas. Desenvolveram-se os bioensaios em câmaras de germinação, à temperatura constante de $25^{\circ} \mathrm{C}$ e fotoperiodo de 12 horas. Cada placa de Petri de $9,0 \mathrm{~cm}$ de diâmetro, forrada com uma folha de papel, recebeu 25 sementes de cada planta receptora. Consideraram-se sementes germinadas aquelas que apresentavam raiz primária com extensão igual ou superior a 2,0 mm (Juntila, 1976; Duram \& Tortosa, 1985).

Selecionaram-se as sementes das espécies receptoras Mimosa pudica (malícia) e Senna obtusifolia (mata-pasto) uniformemente quanto a tamanho, formato e coloração (Labouriau, 1983), coletadas no Campo Experimental da Embrapa Amazônia Oriental, localizado em Belém, Estado do Pará, as quais passaram por processo de limpeza e foram tratadas visando à quebra da dormência, via imersão em ácido sulfúrico (Souza Filho et al., 1998). 
Os bioensaios de desenvolvimento da raiz foram desenvolvidos nas mesmas condições do da germinação, tendo por diferença o fotoperíodo de 24 horas. Cada placa de Petri de $9,0 \mathrm{~cm}$ de diâmetro, forrada com uma folha de papel-filtro qualitativo, recebeu três sementes pré-germinadas, isto é, com aproximadamente três dias de germinação.

\section{Outros procedimentos experimentais}

Em todos os bioensaios, a concentração de teste foi de 1,0\%. Cada placa de Petri de $9,0 \mathrm{~cm}$ de diâmetro recebeu $3,0 \mathrm{~mL}$ da solução. Adicionou-se a solução-teste apenas uma vez, quando do início de cada bioensaio; a partir de então, acrescentou-se apenas água destilada, sempre que necessário. Após a adição das soluções, deixava-se evaporar o solvente e adicionava-se água destilada, em volume correspondente, mantendo-se, dessa forma, a concentração original.

\section{Delineamento experimental e análise estatistica dos dados}

Para todos os bioensaios, utilizou-se o delineamento experimental inteiramente casualizado com três repetições, em esquema fatorial com três fatores (3[plantas doadoras] $\mathrm{x}$ 3 [frações da planta] x 2[extratos brutos]), utilizando-se, como tratamento testemunha água destilada. Analisaram-se os dados pelo teste $\mathrm{F}$, e as médias foram comparadas pelo teste de Tukey a 5\%, com o auxílio do programa SAS (SAS, 1989). Os dados foram transformados para arc. sen. $\sqrt{ } \mathrm{x}$.

\section{RESULTADOS E DISCUSSÃO}

$\mathrm{Na}$ avaliação de atividade alelopática de extratos brutos, um fator importante a ser considerado são os efeitos aditivos entre alelopatia e potencial osmótico. Essa relação pode tanto superestimar a atividade alelopática do extrato, como atribuir atividade alelopática a extratos sem tal propriedade (Wardle et al., 1992). Existe, portanto, necessidade de separar esses efeitos para que os resultados obtidos reflitam, na integra, as reais potencialidades dos extratos. Neste estudo, utilizou-se a concentração de 1,0\%; para concentrações igual ou ligeiramente acima, a contribuição do potencial osmótico pode ser desconsiderada (Souza Filho \& Alves, 2000b). Os resultados encontrados neste trabalho podem ser atribuídos, exclusivamente, aos efeitos da atividade alelopática dos extratos sobre a germinação de sementes e o desenvolvimento da raiz.

Houve significância para a interação entre espécie de planta doadora e partes da planta doadora (Tabela 1). Diferenças consideráveis na intensidade dos efeitos são observadas tanto entre as espécies doadoras como entre as partes das plantas. Observa-se que cascas, folhas e galhos de $C$. duckei apresentaram baixo potencial para inibir a germinação de sementes de malícia e mata-pasto. Para as espécies C. martii e C. reticulata, as frações folhas e galhos promoveram inibições em torno de $60 \%$ e $50 \%$, respectivamente, com as folhas promovendo inibições ligeiramente mais intensas. Das três espécies, apenas as cascas de $C$. reticulata apresentaram-se efetivas na inibição da germinação, e somente para as sementes de malicia. Comparativamente, as inibições da germinação das sementes foram mais intensas em malícia do que em matapasto, exceto para os efeitos de C. Duckei.

Na Tabela 2 encontra-se o desdobramento da interação entre espécie doadora e tipo de extrato, para a germinação da espécie malícia. À semelhança do observado na Tabela 1, C. duckei apresentou baixo potencial inibitório na germinação das sementes de malícia tanto para o extrato hexânico como para o etanólico, observando-se ligeira vantagem para o primeiro. Para as outras duas espécies, o extrato

Tabela 1 - Variações nos efeitos alelopáticos sobre a germinação de sementes de duas plantas daninhas, em função da planta doadora e da parte da planta doadora. Dados expressos em percentual de inibição em relação ao tratamento testemunha - água destilada

\begin{tabular}{|c|l|c|c|c|}
\hline \multirow{2}{*}{$\begin{array}{c}\text { Planta } \\
\text { receptora }\end{array}$} & \multirow{2}{*}{$\begin{array}{c}\text { Parte das } \\
\text { plantas }\end{array}$} & \multicolumn{3}{|c|}{ Planta doadora } \\
\cline { 3 - 5 } & C. duckei & C. martii & C. reticulata \\
\hline \multirow{3}{*}{ Malícia } & Cascas & $12,2 \mathrm{Ab}$ & $6,3 \mathrm{Bc}$ & $30,5 \mathrm{Ca}$ \\
\cline { 2 - 5 } & Folhas & $6,0 \mathrm{Bc}$ & $60,0 \mathrm{Aa}$ & $52,8 \mathrm{Ab}$ \\
\cline { 2 - 5 } & Galhos & $4,7 \mathrm{Cc}$ & $59,0 \mathrm{Aa}$ & $50,0 \mathrm{Bb}$ \\
\hline \multirow{3}{*}{ Mata-pasto } & Cascas & $8,2 \mathrm{Ba}$ & $5,7 \mathrm{Ba}$ & $8,6 \mathrm{Aa}$ \\
\cline { 2 - 5 } & Folhas & $8,8 \mathrm{Ba}$ & $10,5 \mathrm{Aa}$ & $6,6 \mathrm{Aa}$ \\
\cline { 2 - 5 } & Galhos & $13,2 \mathrm{Aa}$ & $14,5 \mathrm{Aa}$ & $7,0 \mathrm{Ab}$ \\
\hline
\end{tabular}

Médias seguidas de letras iguais, maiúsculas na coluna e minúsculas na linha, não diferem pelo teste de Tukey (5\%). 
Tabela 2 - Variações na atividade alelopática inibitória da germinação de sementes da planta daninha malícia, em função da planta doadora e do tipo de extrato. Dados expressos em percentual de inibição em relação ao tratamento testemunha - água destilada

\begin{tabular}{|l|l|c|c|c|}
\hline \multirow{2}{*}{$\begin{array}{c}\text { Planta } \\
\text { receptora }\end{array}$} & \multirow{2}{*}{$\begin{array}{l}\text { Tipo de } \\
\text { extrato }\end{array}$} & \multicolumn{3}{|c|}{ Planta doadora } \\
\cline { 3 - 5 } & C. duckei & C. martii & C. reticulata \\
\hline \multirow{2}{*}{ Malícia } & Hexânico & $10,0 \mathrm{Ab}$ & $17,7 \mathrm{Ba}$ & $6,7 \mathrm{Bc}$ \\
\cline { 2 - 5 } & Etanólico & $5,2 \mathrm{Bc}$ & $66,7 \mathrm{Ab}$ & $82,2 \mathrm{Aa}$ \\
\hline
\end{tabular}

Médias seguidas de letras iguais, maiúsculas na coluna e minúsculas na linha, não diferem pelo teste de Tukey (5\%).

etanólico apresentou vantagem expressiva na inibição da germinação das sementes, sendo a diferença, em relação ao extrato hexânico, da ordem de $73 \%$, em C. martii, e de $92 \%$, em C. reticulata.

Em face da ausência de interação significativa $(p<0,05)$ entre espécie doadora e tipo de extrato, para mata-pasto, os efeitos são apresentados isoladamente. Observa-se, novamente, o baixo potencial das três espécies doadoras para inibir a germinação das sementes de mata-pasto; $C$. reticulata foi a que apresentou potencial superioridade $(\mathrm{p}<0,05)$ sobre as demais espécies (Figura 1). Na comparação entre os tipos de extrato, a intensidade dos efeitos, à semelhança do observado em comparações anteriores, também foi baixa, atingindo o máximo de $12 \%$ de inibição pelo extrato etanólico, que foi superior $(\mathrm{p}<0,05)$ ao extrato hexânico (Figura 2).

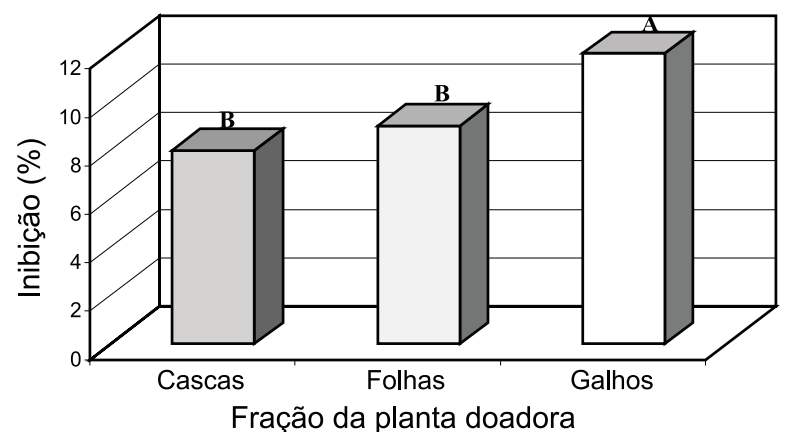

Médias seguidas de letras iguais não diferem pelo teste de Tukey $(5 \%)$.

Figura 1 - Efeitos médios de diferentes partes de plantas de Copaifera sobre a germinação de sementes da planta daninha mata-pasto.
Registrou-se superioridade do extrato etanólico na inibição da germinação das sementes, independentemente da planta receptora e da parte da planta; as folhas $(64,5 \%)$ e os galhos $(64,3 \%)$ mostraram as mais altas taxas de inibição para extrato etanólico (Tabela 3). Os efeitos promovidos sobre mata-pasto foram de baixa intensidade quando se consideraram aqueles promovidos sobre malícia, evidenciando mais uma vez a diferença na sensibilidade entre as duas espécies. O conjunto das informações das Tabelas 2 e 3 mostra que a atividade alelopática inibitória da germinação das sementes das três espécies está muito mais associada às substâncias químicas de alta polaridade, presentes especialmente em folhas e galhos das espécies C. martii e C. reticulata.

Os efeitos sobre o desenvolvimento da raiz (Tabela 4) apresentaram algumas variações importantes em relação àqueles sobre a germinação das sementes (Tabela 1). A intensidade dos efeitos sobre malícia e mata-pasto não diferiu tanto quanto no bioensaio de germinação, sendo, em alguns casos, em matapasto, superiores àqueles verificados sobre malícia, especialmente em se tratando dos efeitos promovidos pelos extratos de casca. Aparentemente, os compostos químicos presentes nas frações das três espécies mostram maior especificidade para inibir o desenvolvimento da raiz do que a germinação. A espécie C. duckei - que revelou baixo potencial para inibir a germinação das sementes

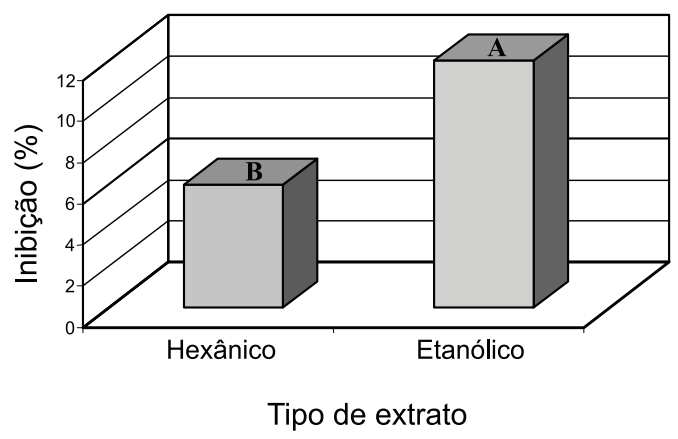

Médias seguidas de letras iguais não diferem pelo teste de Tukey $(5 \%)$.

Figura 2 - Efeitos médios de dois tipos de extratos alcoólicos de três espécies de Copaifera sobre a germinação de sementes da planta daninha mata-pasto.

Planta Daninha, Viçosa-MG, v. 28, n. 4, p. 743-751, 2010 
Tabela 3 - Variações na atividade alelopática inibitória da germinação de sementes de duas plantas receptoras em função da parte da planta doadora e do tipo de extrato. Dados expressos em percentual de inibição em relação ao tratamento testemunha - água destilada

\begin{tabular}{|c|l|c|c|c|}
\hline \multirow{2}{*}{$\begin{array}{c}\text { Planta } \\
\text { receptora }\end{array}$} & \multirow{2}{*}{$\begin{array}{l}\text { Tipo de } \\
\text { extrato }\end{array}$} & \multicolumn{3}{|c|}{ Parte das plantas doadoras } \\
\cline { 3 - 5 } Malícia & Cascas & Folhas & Galhos \\
\cline { 2 - 5 } & Etanánico & $7,4 \mathrm{Bc}$ & $15,0 \mathrm{Ba}$ & $12,0 \mathrm{Bb}$ \\
\hline \multirow{2}{*}{ Mata-pasto } & $25,2 \mathrm{Ab}$ & $64,5 \mathrm{Aa}$ & $64,3 \mathrm{Aa}$ \\
\hline & Hexânico & $3,3 \mathrm{Bb}$ & $6,0 \mathrm{Bb}$ & $10,0 \mathrm{Ba}$ \\
\cline { 2 - 5 } & Etanólico & $11,7 \mathrm{Aa}$ & $11,3 \mathrm{Aa}$ & $13,0 \mathrm{Aa}$ \\
\hline
\end{tabular}

Médias seguidas de letras iguais, maiúsculas na coluna e minúsculas na linha, não diferem pelo teste de Tukey (5\%).

das duas espécies receptoras - mostrou maior capacidade deletéria no desenvolvimento da raiz dessas espécies. Em relação ao fator parte da planta doadora, por outro lado, não se observou clara predominância de uma dada fração. Quanto ao desenvolvimento da raiz de malícia, por exemplo, os efeitos de maior grandeza foram promovidos pelo extrato das folhas de $C$. reticulata e $C$. duckei, enquanto para C. martii o destaque foi o extrato das cascas. Para mata-pasto, os resultados foram diferentes, com maiores intensidades inibitórias promovidas pelos extratos de cascas de $C$. reticulata e $C$. martii e de folhas de C. duckei.

Quanto aos efeitos da interação tipo de extrato e espécie de planta doadora sobre o desenvolvimento da raiz, observou-se superioridade $(\mathrm{p}<0,05)$ dos efeitos alelopáticos do extrato etanólico sobre malícia, em $C$. reticulata e C. martii, e do extrato hexânico, em C. duckei (Tabela 5). No tocante ao mata-pasto, os efeitos foram similares em C. reticulata e C. duckei, enquanto em C. martii não houve diferenças $(p>0,05)$ entre os dois extratos, embora os efeitos do extrato hexânico tenham sido superiores. Comparativamente aos efeitos sobre a germinação das sementes de malícia (Tabela 2), observaram-se algumas diferenças de intensidade inibitória, como, por exemplo, efeitos mais intensos no desenvolvimento da raiz promovidos pelos extratos de C. duckei, enquanto aqueles efetivados pelo extrato etanólico foram de menor magnitude. No mesmo sentido, o extrato hexânico apresentou baixos efeitos em todas as três plantas doadoras.
Extratos hexânicos de cascas e folhas foram mais eficientes na inibição do desenvolvimento da raiz das duas espécies receptoras; já no extrato etanólico verificaram-se inibições mais intensas dos galhos (Tabela 6). À semelhança do que já foi comentado, os extratos hexânicos apresentaram maior atividade inibitória sobre o desenvolvimento da raiz do que da germinação (Tabela 2). Contrariamente, o extrato etanólico foi mais eficiente na inibição da germinação, sobretudo para os efeitos sobre a espécie malícia. Independentemente do tipo de extrato, galhos e folhas foram mais fitotóxicos para malícia do que para mata-pasto; ao contrário, extratos de cascas foram mais efetivos sobre mata-pasto.

Os resultados apresentados nas Tabelas 5 e 6 dão sustentação à tese de que a utilização, tão-somente de extratos de alta polaridade (por exemplo, o etanol) na fase inicial de prospecção

Tabela 4 - Variações nos efeitos alelopáticos sobre o desenvolvimento da raiz de duas plantas daninhas, em função da planta doadora e da parte da planta doadora. Dados expressos em percentual de inibição em relação ao tratamento testemunha - água destilada

\begin{tabular}{|l|l|l|c|c|}
\hline \multirow{2}{*}{$\begin{array}{c}\text { Planta } \\
\text { receptora }\end{array}$} & Parte das & \multicolumn{3}{|c|}{ Planta doadora } \\
\cline { 3 - 5 } & plantas & C. duckei & C. martii & C. reticulata \\
\hline \multirow{3}{*}{ Malícia } & Cascas & $25,8 \mathrm{Cb}$ & $39,6 \mathrm{Aa}$ & $41,1 \mathrm{Ca}$ \\
\cline { 2 - 5 } & Folhas & $46,5 \mathrm{Ab}$ & $30,8 \mathrm{Bc}$ & $51,2 \mathrm{Aa}$ \\
\cline { 2 - 5 } & Galhos & $32,5 \mathrm{Bb}$ & $31,0 \mathrm{Bb}$ & $46,0 \mathrm{Ba}$ \\
\hline \multirow{3}{*}{ Mata-pasto } & Cascas & $30,5 \mathrm{Ac}$ & $55,7 \mathrm{Aa}$ & $42,5 \mathrm{Ab}$ \\
\cline { 2 - 5 } & Folhas & $34,6 \mathrm{Aa}$ & $28,8 \mathrm{Bb}$ & $21,6 \mathrm{Bb}$ \\
\cline { 2 - 5 } & Galhos & $20,0 \mathrm{Bb}$ & $25,0 \mathrm{Bb}$ & $24,3 \mathrm{Ba}$ \\
\hline
\end{tabular}

Médias seguidas de letras iguais, maiúsculas na coluna e minúsculas na linha, não diferem pelo teste de Tukey (5\%).

Tabela 5 - Variações na atividade alelopática inibitória do desenvolvimento da raiz de duas plantas daninhas, em função da planta doadora e do tipo de extrato. Dados expressos em percentual de inibição em relação ao tratamento testemunha - água destilada

\begin{tabular}{|l|l|c|c|c|}
\hline \multirow{2}{*}{$\begin{array}{c}\text { Planta } \\
\text { receptora }\end{array}$} & \multirow{2}{*}{$\begin{array}{l}\text { Tipo de } \\
\text { extrato }\end{array}$} & \multicolumn{3}{|c|}{ Planta doadora } \\
\cline { 3 - 5 } & C. duckei & C. martii & C. reticulata \\
\hline \multirow{2}{*}{ Malícia } & Hexânico & $45,9 \mathrm{Aa}$ & $25,9 \mathrm{Bc}$ & $41,0 \mathrm{Bb}$ \\
\cline { 2 - 5 } & Etanólico & $24,0 \mathrm{Bc}$ & $41,7 \mathrm{Ab}$ & $51,2 \mathrm{Aa}$ \\
\hline \multirow{2}{*}{ Mata-pasto } & Hexânico & $33,1 \mathrm{Ab}$ & $37,5 \mathrm{Aa}$ & $25,8 \mathrm{Bc}$ \\
\cline { 2 - 5 } & Etanólico & $23,6 \mathrm{Bb}$ & $35,5 \mathrm{Aa}$ & $33,1 \mathrm{Aa}$ \\
\hline
\end{tabular}

Médias seguidas de letras iguais, maiúsculas na coluna e minúsculas na linha, não diferem pelo teste de Tukey (5\%). 
de atividade alelopática de uma dada espécie de planta pode não refletir suas reais potencialidades como agente alelopático e, ao mesmo tempo, levar a interpretações equivocadas sobre a planta em estudo. É aceito que os extratos polares podem fornecer compostos bioativos de alta expressão, especialmente aqueles relativos aos compostos fenólicos. $\mathrm{Na}$ literatura encontram-se bons exemplos que reforçam essa afirmação (Chon et al., 2002; Leu et al., 2002; Xuan et al., 2003). Entretanto, a utilização de extratos apolares (como o hexânico) não pode deixar de ser considerada. As informações disponiveis mostram que as plantas produzem um sem-número de compostos quimicamente diversificados, com ampla variação no tocante à polaridade, e que a distribuição na planta não obedece a um padrão definido. Em muitos estudos, efeitos alelopáticos potentes de composto de baixa polaridade, como os monoterpenos, monoterpenos oxigenados e sesquiterpenos, são encontrados (Isman, 2000; Abraham et al., 2000; Barney et al., 2005; Nishida et al., 2005). Neste trabalho, o extrato hexânico apresentou baixa atividade alelopática inibitória da germinação das sementes, mas foi inegável a expressão dos seus efeitos sobre o desenvolvimento da raiz (Tabelas 5 e 6), o que, em si, já justifica seu uso em bioensaios de prospecção inicial de atividade alelopática, especialmente naqueles casos em que não há informações sobre a planta estudada - mesmo porque possibilita o isolamento e identificação de substâncias químicas com atividade alelopática relevante.

Em estudos de alelopatia, fatores determinantes nas intensidades dos efeitos são: espécie doadora, parte da planta analisada e espécie receptora. Verificaram-se variações em função desses aspectos, em que, comparativamente, $C$. martii e $C$. reticulata apresentaram maior potencial para inibir a germinação de sementes, notadamente os extratos de folhas e galhos. Para essas espécies, a principal fonte de substâncias químicas com atividades alelopáticas são as polares. Para a espécie C. duckei, baixa efetividade para inibir a germinação de sementes foi observada e a tendência foi de folhas e cascas se constituírem nas principais fontes de substâncias químicas com potencial inibitório. Essa atividade está relacionada, preferencialmente, à presença de compostos químicos apolares,
Tabela 6 - Variações na atividade alelopática inibitória do desenvolvimento da raiz de duas plantas daninhas, em função da parte da planta doadora e do tipo de extrato. Dados expressos em percentual de inibição em relação ao tratamento testemunha - água destilada

\begin{tabular}{|l|l|c|c|c|}
\hline \multirow{2}{*}{$\begin{array}{c}\text { Planta } \\
\text { receptora }\end{array}$} & \multirow{2}{*}{$\begin{array}{l}\text { Tipo de } \\
\text { extrato }\end{array}$} & \multicolumn{3}{|c|}{ Parte das plantas doadoras } \\
\cline { 3 - 5 } & Cascas & Folhas & Galhos \\
\hline \multirow{2}{*}{ Malícia } & Hexânico & $38,6 \mathrm{Ab}$ & $45,8 \mathrm{Aa}$ & $28,3 \mathrm{Bc}$ \\
\cline { 2 - 5 } & Etanólico & $32,4 \mathrm{Bc}$ & $39,9 \mathrm{Bb}$ & $44,6 \mathrm{Aa}$ \\
\hline \multirow{2}{*}{ Mata-pasto } & Hexânico & $45,0 \mathrm{Aa}$ & $29,1 \mathrm{Ab}$ & $22,3 \mathrm{Bc}$ \\
\cline { 2 - 5 } & Etanólico & $40,7 \mathrm{Ba}$ & $25,1 \mathrm{Bb}$ & $26,4 \mathrm{Ab}$ \\
\hline
\end{tabular}

Médias seguidas de letras iguais, maiúsculas na coluna e minúsculas na linha, não diferem pelo teste de Tukey (5\%).

notadamente em relação aos efeitos promovidos sobre o desenvolvimento da raiz. No geral, malícia mostrou-se mais sensivel aos efeitos alelopáticos do que mata-pasto, praticamente em todos os bioensaios, se bem que em alguns momentos as diferenças não foram estatisticamente significativas. Quando se consideraram as variações nas intensidades dos efeitos inibitórios sobre a germinação de sementes e o desenvolvimento da raiz, diferenças foram observadas em função da espécie receptora. Para malícia a germinação foi mais inibida, enquanto para mata-pasto foi o desenvolvimento da raiz.

Tendo por base o valor de $50 \%$ de inibição como um padrão satisfatório para aquilatar as potencialidades alelopáticas de um extrato (Dudai et al., 1999), verifica-se, no bioensaio de germinação, que apenas os extratos de folhas e galhos de $C$. martii e $C$. reticulata (Tabela 1) e o extrato etanólico de folhas e galhos (Tabelas 2 e 3 ) atenderam a esse valor, em relação à espécie malícia. Para os efeitos sobre o desenvolvimento da raiz, apenas o extrato etanólico de folhas de $C$. reticulata atendeu a esse requisito, e somente para a espécie receptora malícia. Considerando apenas esse aspecto, pode-se inferir que C. reticulata apresentou maior atividade alelopática e que as folhas são a principal fonte de substâncias polares com atividade alelopática. Considerando-se apenas a germinação das sementes, C. martii apresentou grande potencialidade, merecendo destaque o extrato etanólico das folhas e galhos.

Variações na atividade alelopática de diferentes espécies de Copaifera foram observadas, 
em função da parte da planta e da polaridade das substâncias envolvidas na atividade. Quanto às espécies C. martii e C. reticulata, folhas e galhos constituem as principais fontes de substâncias químicas polares com atividade alelopática. Substâncias químicas apolares presentes nessas espécies estão mais envolvidas em inibições do desenvolvimento da raiz e distribuídas praticamente em todas as partes das plantas. Para C. duckei, efeitos específicos sobre o desenvolvimento da raiz foram o destaque, sendo as folhas a principal fonte de substâncias químicas apolares com atividade alelopática.

\section{LITERATURA CITADA}

ABRAHAM, D. et al. Effects of four monoterpens on germination, primary root and mitochondrial respiration of maize. J. Chem. Ecol., v. 26, p. 611-624, 2000

ARRUDA, M. S. P. et al. Potential allelochemicals isolated from Pueraria phaseoloides. Allelopathy J., v. 15, n. 2, p. 211-220, 2005.

BARNEY, J. N.; HAY, A. G.; WESTON, L. A. Isolation and characterization of allelopathic volatiles from mugworth (Artemisia vulgaris), J. Chem. Ecol., v. 31, n. 2, p. 247265, 2005.

BERGER, J.; SCHAGERL, M. Allelopathic activity of Chara aspera. Hydrobiologia, v. 501, p. 109-115, 2003.

CHON, S. U. et al. Effects of alfafa leaf extracts and phenolic allelochemicals on early seedling growth and root morphology of alfafa and barnyard grass. Crop Protec., v. 21, p. $1077-1082,2002$

CUNHA, A. G. Dicionário histórico das palavras portuguesas de origem tupi. Brasília: Melhoramentos, 1999. $120 \mathrm{p}$

DUCKE, A. Notas sobre a flora neotrópica II. As leguminosas da Amazônia Brasileira. 2.ed. Belém: 1949 p. 248. (Boletim Técnico do Instituto Agronômico do Norte, 1)

DUDAI, N. et al. Essential oils as allelochemicals and their potential use as bioerbicides. J. Chem. Ecol., v. 25, n. 5, p. $1079-1089,1999$

DURAM, J. M.; TORTOSA, M. E. The effects of mechanical and chemical scarification on germination of charlock (Sinapsis arvensis L.) seeds. Seed Sci. Technol., v. 13 , n. 1 , p. $155-163,1985$

Planta Daninha, Viçosa-MG, v. 28, n. 4, p. 743-751, 2010
DWYER, J. D. The Central American, West Indian and South American species of copaifera (Caesalpiniaceae). Brittonia, v. 7, n. 3, p. $143-172,1951$

FERREIRA, A. B. H. Novo dicionário da língua portuguesa. Rio de Janeiro: Nova Fronteira, 1988. 1498 p.

IQBAL, Z.; FURUBAYASHI, A.; FUJI, Y. Allelopathic effect of leaf debris, leaf aqueous extract and rhizosphere soil of Ophiopogon japonicus Ker-Gawler on the growth of plants. Weed Biol. Manag., v. 4, n. 1, p. 43-48, 2004.

ISMAN, M. B. Plant essential oils for pest and disease management. Crop Protec., v. 19, n. 8, p. 603-608, 2000.

JUNTILA, O. Seed and embryo germination in $S$. vulgaris and $S$. reflexa as effects by temperature during seed development. Physiol. Plant., v. 29, p. 264-268, 1976.

LABOURIAU, L. G. A germinação de sementes. Washington: OEA, 1983. $170 \mathrm{p}$.

LEU, E. et al. Polyphenolic allelochemicals from the aquatic angiosperm Myriophyllum spicatum in inhibit photosystem II Plant Physiol., v. 130, p. 2111-2118, 2002.

LEWIS G.P.; MACKINDER,B.; LOCK, M. (Eds.). Legume of the world. Kew: Royal Botanic Garden, 2005. 577 p.

LOBO, L. T. et al. Potencial alelopático de catequinas de Tachigali myrmecophila (Leguminosae). Química Nova., v. 31, n. 3, p. 493-497, 2008.

MARCHIORI, J. N. C. Dendrologia das angiospermas leguminosas. Santa Maria: Universidade Federal do Rio grande do Sul, 1997. p. 11-13.

MARTINS-DA-SILVA, R. C. V. Taxonomia das espécies de Copaifera L. (Leguminosae Caesalpinoideae) ocorrentes na Amazônia Brasileira. 2006. 258 f. Tese (Doutorado em Botância) - Universidade Federal do Rio de Janeiro, Rio de Janeiro, 2006.

NISHIDA, N. et al. Allelopathic effects of volatile monoterpenoides produc by Salvia leucophylla: Inhibition of cell proliferation and DNA synthesis in the root apical meristem of Brassica campestris Seedlings. J. Chem. Ecol., v. 31, n. 5, p. 1187-1202, 2005.

PERIOTTO, F.; PEREZ, S. C. J. G. A.; LIMA, M. I. S. Efeito alélopático de Andira humilis Mart. Ex Benth na germinação e no crescimento de Lactuca sativa L. e Raphanus sativus L. Acta. Bot. Bras., v. 18, n. 3, p. 425-430, 2004.

RICE, E. L. Allelopathy: an overview. In: WALLER, G. R. Allelochemical, role in agriculture and forestry. Washington, D.C.: American Chemical Society, 1987. p.7-22. (ACS. Symposium Series, 330). 
SANTOS, L. S. et al. Allelochemicals isolated from the leaves of Virola michelli Heckel. Allelopathy J., v. 20, n. 1, p. $2235-2242,2007$.

SANTOS, L. S. et al. Atividade alelopática de substâncias químicas isoladas do capim-marandu e suas variações em função do pH. Planta Daninha, v. 26, n. 3, p. 531-538, 2008.

SAS - INSTITUTE. Statistical Analysis System. User's guide. Version 6.4. ed. Cary: 1989. 846 p.

SHIRAISHI, S. et al. Allelopathci activity of leaching from dry leaves and exudates from roots of ground cover plants assayed on agar. Weed Biol. Manag., v. 2. p. 133-142, 2002.

SILVA, M. F. et al. As leguminosas da Amazônia Brasileira, lista prévia. Acta Bot. Bras., v. 2, n. 1, p. 193-237, 1989.

SOUZA FILHO, A. P. S.; ALVES, S. M. Efeitos potencialmente alelopáticos e autotóxicos em Pueraria phaseoloides. IN: REUNIÃO ANUAL DA SOCIEDADE BRASILEIRA DE ZOOTECNIA, 35., 1998., Botucatu. Anais... Botucatu: SBZ, 1998. p. 88-89.

SOUZA FILHO, A. P. S.; ALVES, S. M. Allelopathic potential of pasture weeds: efects on forage legume. Plant Reg. Soc. Am., v. 28, n. 4, p. 146-156, 2000a.

SOUZA FILHO, A. P. S.; ALVES, S. M. Potencial alelopático de plantas de acapu (Vouacapoua americana): efeitos sobre plantas daninhas de pastagens. Planta Daninha, v. 18, n. 3, p. $435-441,2000$ b.
SOUZA FILHO, A. P. S.; FONSECA, M. L.; ARRUDA, M. S. P. Substâncias químicas com atividades alelopáticas presentes nas folhas de Parkia pendula (Leguminosae) Planta Daninha, v. 23, n. 4, p. 565-573, 2005.

SOUZA FILHO, A. P. S.; RODRIGUES, L. R. A.; RODRIGUES, T. J. D. Inibição da germinação e alongamento da radícula de invasoras de pastagens pelos extratos aquosos de gramíneas forrageiras tropicais. Past. Trop., v. 19, n. 1, p. $45-50,1997$

SOUZA FILHO, A. P. S. et al. Effects of aqueous extracts of Leucaena on germination and radicle elongation of three forage grasses. In: MACIAS, F. A. et al. (Eds.). Recent advances in Allelopathy, Cádiz: International Allelopathy Society, 1999. v. 1. p. 391-395.

TEFERA, T. Allelopathci effects of Parthenium hysterophorus extracts on seed germination and seedling growth of Eragrostis tef. J. Agron. Crop Sci., v. 188, p. 306-310, 2002.

WARDLE, D. A.; NICHOLSON, K. S.; RAHMAN, A. Influence os pasture grass and legumes swards on seedling emergence and growth of Carduus nutans L. and Cirsium vulgare L. Weed Res., v. 32, n. 2, p. 119-28, 1992.

WOJCIECHOWSKI, M. F.; LAVIN, M. \& SANDERSON, M. J. A phylogeny of legumes (Leguminosae) based on analysis of plastid matK gene resolves many well-supported subclades within the family. Am J. Bot., v. 91, n. 11, p. 1846-1862, 2004. 